\title{
Contaminação de solo por ovos de Toxocara spp. e outros geo-helmintos em comunidade rural do Pantanal Mato-Grossense, Brasil
}

\section{Soil contamination by Toxocara spp. eggs and other geohelminths in a rural community from the Pantanal Mato-Grossense area, Brazil}

\author{
Selma Samiko Miyazaki ONUMA ${ }^{1,2}$; Andréia Lima Tomé MELO루 ${ }^{1}$ Mathias Bassinello STOCCO ${ }^{3}$; \\ Vamilton Alvares SANTARÉM ${ }^{4}$; Daniel Moura AGUIAR ${ }^{1}$ \\ ${ }^{1}$ Universidade Federal de Mato Grosso, Hospital Veterinário, Laboratório de Virologia e Rickettsioses, Cuiabá - MT, Brasil \\ ${ }^{2}$ Instituto Chico Mendes de Conservação da Biodiversidade (ICMBio), Estação Ecológica de Taiamã, Cáceres - MT, Brasil \\ ${ }^{3}$ Universidade Federal de Mato Grosso, Hospital Veterinário, Cuiabá - MT, Brasil \\ ${ }^{4}$ Universidade do Oeste Paulista, Hospital Veterinário, Laboratório de Medicina Veterinária Preventiva II,
}

Presidente Prudente - SP, Brasil

\begin{abstract}
Resumo
A investigação da contaminação do solo por enteroparasitos já foi efetuada em várias regiões do Brasil, principalmente em locais que podem apresentar riscos à saúde humana, como creches e praças públicas. No presente trabalho, foi relatada a contaminação do solo por ovos de Toxocara spp., Ascaris spp., tricostrongilídeos e oocistos de protozoários em uma comunidade rural localizada no Pantanal Mato-Grossense. Os resultados do presente estudo ressaltam o risco a que podem estar expostos os moradores de comunidades em condições precárias de habitação e saneamento com relação à infecção por parasitas.
\end{abstract}

Palavras-chave: Contaminação do solo. Parasitas. Zoonoses.

\begin{abstract}
Studies concerning soil contamination by enteroparasites have been carried out in different regions of Brazil, particularly in areas that may represent risks to human health, such as daycare playgrounds and public parks. In this study, contamination of soil by eggs of Toxocara spp., Ascaris spp., trichostrongylids as well as by oocysts of protozoa was reported in a rural community located close to the Pantanal Mato-Grossense, Brazil. The results highlight the risk of people living in communities with precarious sanitary conditions in relation to parasitic infection.
\end{abstract}

Keywords: Soil contamination. Parasites. Zoonosis.

Parasitas do gênero Toxocara, em especial Toxocara canis e Toxocara cati, infestam o intestino de canídeos e felídeos e são os principais agentes da toxacaríase, uma antropozoonose cosmopolita denominada larva migrans vísceral/ocular. A doença apresenta quadro clínico variável e inespecífico em consequência das reações mecânicas e imunológicas provocadas pela presença de larvas (ANDRADE, 2000). Cães e gatos têm papel relevante na transmissão da doença aos humanos a partir da eliminação de ovos nas fezes em áreas públicas (SANTARÉM; SARTOR; BERGAMO, 1998). A contaminação do solo por Toxocara spp. em diferentes ambientes, assim como por outros geo-helmintos tem sido confirmada, o que ressalta a importância destas parasitoses para a saúde pública (SANTARÉM; SARTOR; BERGAMO, 1998; TIYO et al., 2008; CASSENOTE et al., 2011). Entretanto, são escassas as informações sobre contaminação por esses parasitas em áreas pouco urbanizadas ou próximas a ambientes rurais ou silvestres. Diante do exposto, o

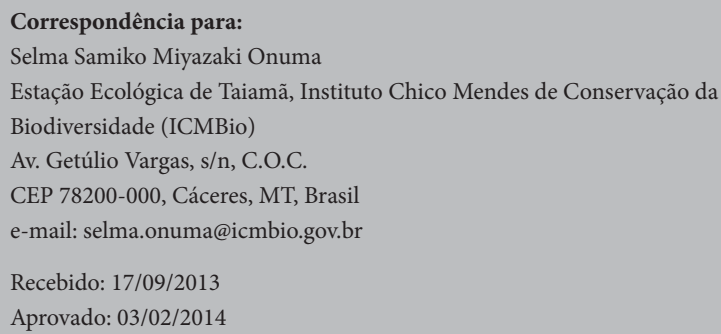


presente trabalho foi delineado para avaliar a contaminação do solo por Toxocara spp. e outros geo-helmintos, em comunidade ribeirinha localizada no município de Corumbá/Mato Grosso do Sul, no entorno do Parque Nacional do Pantanal Mato-Grossense.

O estudo foi conduzido no mês de dezembro de 2011, período equivalente ao início da época de chuvas, na comunidade da Barra de São Lourenço (17052'53,23"S/57²6'48,41"W e 17056’38,18”S/57²7’54,22”W), localizada a aproximadamente $220 \mathrm{~km}$ da zona urbana de Corumbá pelo rio Paraguai, e a $10 \mathrm{~km}$ ao sul do Parque Nacional do Pantanal Mato-Grossense, ao longo da margem esquerda do rio. O Pantanal é a maior planície alagável do planeta, onde as flutuações sazonais do nível das águas regulam os processos ecológicos que ali existem (JUNK; BAYLEY; SPARKS, 1989) e, consequentemente, exercem grande influência na dinâmica populacional da região. A temperatura anual média é de $25,8^{\circ} \mathrm{C}$ e a precipitação anual média varia de 800 a $1.400 \mathrm{~mm}$, sendo que nos meses de outubro a março ocorrem mais de 70\% da pluviosidade média anual (CADAVID GARCIA, 1981). A amostragem foi realizada por conveniência em locais onde ainda havia barrancos marginais bem secos, dos quais era possível a colheita de amostras de solo. No momento do estudo, 12 famílias habitavam a comunidade, com aproximadamente 60 pessoas, em dique marginal ao rio Paraguai, caracterizado por solo argiloso do tipo hidromórfico e de aparente vulnerabilidade à erosão. $\mathrm{O}$ rio garante o abastecimento da comunidade a partir da pesca para subsistência, além da água para consumo e higiene da população. As distâncias entre as residências podem variar de 50 metros a mais de 3 quilômetros, a iluminação é efetuada principalmente com lamparinas e as condições de saneamento básico são praticamente inexistentes. Os cães (32) e um gato, presentes na comunidade no momento da amostragem, tinham livre acesso ao interior das residências e aos lotes vizinhos, uma vez que não havia separação física (cercas e muros) entre as propriedades. Pequenas criações de bovinos e aves domésticas fazem parte da atividade econômica e de subsistência dos moradores dessa comunidade e os animais são criados nas adjacências das residências, muitas vezes compartilhando espaços com os moradores e crianças da comunidade. A presença de espécies silvestres é comum no local e em um dos lotes foi notada a existência de uma capivara (Hydrochoerus hydrochaeris) domesticada.

Para avaliação da contaminação ambiental, amostras de $100 \mathrm{~g}$ de solo foram colhidas em oito pontos diferentes, por residência: duas amostras na face frontal, duas nos fundos e duas em cada lateral. As colheitas foram efetuadas após a eliminação das sujidades da superfície, a uma profundidade de $5,0 \mathrm{~cm} \mathrm{e}$ inclinação de $45^{\circ}$. O material coletado foi acondicionado em sacos plásticos, cada um contendo amostras de uma das faces da casa (SANTARÉM et al., 2008), totalizando 48 amostras. O material foi armazenado sob refrigeração $\left(4^{\circ} \mathrm{C}\right)$ até o processamento.

A recuperação dos ovos foi efetuada com a técnica descrita por Dada e Lindquist (1979), com pequenas modificações. Foram retiradas duas alíquotas de um grama por amostra de solo referente a cada face das casas. Em cada alíquota foi adicionada água destilada para obtenção de sedimento, o qual foi submetido à etapa de flutuação de ovos, com solução de sulfato de zinco $\left(\mathrm{d}=1,35 \mathrm{~g} / \mathrm{cm}^{3}\right)$. O processo de flutuação foi repetido mais duas vezes, totalizando-se a leitura de três lâminas em microscopia ótica (objetiva: 10x).

Dos 12 lotes avaliados, sete (58,3\%) estavam contaminados por pelo menos uma estrutura parasitária (Tabela 1). A frequência de contaminação por Toxocara spp. foi de $41,7 \%$ (5/12), valor acima do relatado por Santarém et al. (2008), que recuperaram ovos em $29 \%$ dos lotes em assentamento rural no estado de São Paulo. A recuperação de ovos de Toxocara spp. variou de um a cinco ovos por lote, valores iguais aos encontrados em Mirante de Paranapanema, cidade do interior de São Paulo, também considerada de baixo nível de desenvolvimento social como a da presente pesquisa (SANTARÉM et al., 2010). Porém, esses 
Tabela 1 - Número de estruturas parasitárias recuperadas em amostras de solo peridomiciliar de 12 lotes na comunidade ribeirinha da Barra de São Lourenço, Pantanal Mato-Grossense, Brasil Poconé - 2011

\begin{tabular}{rcccc}
\hline \multicolumn{5}{c}{ Estrutura parasitária recuperada } \\
\hline $\begin{array}{c}\text { Ovos } \\
\text { Toxocara } \\
\text { spp. }\end{array}$ & $\begin{array}{c}\text { Ovos } \\
\text { Tricostrongilídeos }\end{array}$ & $\begin{array}{c}\text { Ovos } \\
\text { Ascaris } \\
\text { spp. }\end{array}$ & $\begin{array}{c}\text { Oocistos } \\
\text { Protozoários }\end{array}$ \\
\hline 1 & - & 2 & - & 2 \\
2 & 5 & - & - & - \\
3 & 2 & 2 & - & - \\
4 & - & - & - & - \\
5 & 2 & 7 & - & - \\
6 & 2 & 1 & - & - \\
7 & - & - & - & - \\
8 & - & - & - & - \\
9 & - & - & - & - \\
10 & - & - & - & 2 \\
11 & 1 & - & 2 & - \\
12 & - & - & - & - \\
\hline
\end{tabular}

valores estão abaixo dos observados em praças públicas de Presidente Prudente, uma das cidades mais populosas do oeste do estado de São Paulo, onde se observou a presença de 1 a 398 ovos por amostra analisada (SANTARÉM; PEREIRA; ALEGRE, 2012). Entretanto, é importante salientar que, além das técnicas utilizadas para a recuperação de ovos do solo serem variáveis, as áreas avaliadas também diferem entre si quanto à sua utilização e adensamento animal. Além disto, os ovos do gênero Toxocara observados nas amostras poderiam ser da espécie T. vitulorum, uma vez que bovinos coabitam as áreas avaliadas.

Os ovos recuperados no presente estudo não estavam embrionados ou larvados. Três (25\%) lotes apresentaram contaminação concomitante com ovos de tricostrongilídeos.
Muitas são as variáveis que podem influenciar na recuperação de formas parasitárias e na viabilidade dos ovos nos solos, incluindo fatores físicos, ambientais e metodológicos. Em alguns estudos foi observada diferença de positividade na contaminação do solo de acordo com a estação do ano (CHIEFFI; MÜLLER, 1978; TIYO et al., 2008; SANTARÉM; PEREIRA; ALEGRE, 2012). De fato, Mello, Mucci e Cutolo (2011) encontraram maior risco de contaminação do solo em períodos com índices de precipitação e temperatura mais elevados. Esta foi a primeira investigação efetuada na região do Pantanal Mato-Grossense, que sofre forte influência do regime hídrico. Não foi possível a realização da colheita de amostras em outros períodos do ano.

Os resultados obtidos no presente trabalho ressaltam o risco a que podem estar expostos os moradores de comunidades como esta, com precárias condições de habitação e saneamento que contribuem para a transmissão de parasitas.

\section{Agradecimentos}

O presente estudo foi apoiado pela Fundação de Amparo à Pesquisa do Estado de Mato Grosso (FAPEMAT - processo 263287/2010). Agradecemos também ao Parque Nacional do Pantanal Mato-Grossense e ao Instituto Chico Mendes de Conservação da Biodiversidade (ICMBio) pelo apoio logístico, ao Conselho Nacional de Desenvolvimento Científico e Tecnolólogico (CNPq) pela Bolsa de Produtividade Científica concedida a DMA e à Coordenação de Aperfeiçoamento de Pessoal de Nível Superior (CAPES) pela bolsa de doutorado concedida a ALTM e de mestrado de MBS. 


\section{Referências}

ANDRADE, L. D. Aspectos clínico-epidemiológicos da toxocaríase humana. Revista de Patologia Tropical, v. 29, p. 147-159, 2000.

CADAVID GARCIA, E. A. Índices técnico-econômicos da região do Pantanal Mato-Grossense. Corumbá: EMBRAPAUEPAE de Corumbá, 1981. 81 p.

CASSENOTE, A. J. F.; NETO, J. M. P.; LIMA-CATELANI, A. R. A.; FERREIRA, A. W. F. Contaminação do solo por ovos de geohelmintos com potencial zoonótico na municipalidade de Fernandópolis, Estado de São Paulo, entre 2007 e 2008. Revista da Sociedade Brasileira de Medicina Tropical, v. 44, n. 3, p. 371$374,2011$.

CHIEFFI, P. P.; MÜLLER, E. E. Estudo da variação mensal na contaminação do solo por ovos de Toxocara sp. (Nematoda, Ascaroidea), na zona urbana do município de Londrina, Estado do Paraná, Brasil. Revista do Instituto Adolfo Lutz, v. 38, p. 13-16, 1978.

DADA, B. J. O.; LINDQUIST, W. D. Prevalence of Toxocara spp. eggs in some public grounds and highway rest areas in Kansas. Journal of Helmintology, v. 53, p. 145- 146, 1979.

JUNK, W. J.; BAYLEY, P. B.; SPARKS, R. E. The flood pulse concept in river-floodplain systems. Canadian Special Publication of Fisheries and Aquatics Sciences, n. 106, p. 110-127, 1989.

MELLO, C. S.; MUCCI, J. L. N.; CUTOLO, S. A. Contaminação parasitária de solo em praças públicas da zona leste de São Paulo,
SP - Brasil e a associação com variáveis metereológicas. Revista de Patologia Tropical, v. 40, n. 3, p. 253-262, jul-set. 2011.

SANTARÉM, V. A.; DIAS, A. P.; FELIX, A.; RODENAS, R. S.; SILVA, A. V. Contaminação por ovos de Toxocara spp. em praças públicas das regiões central e periurbana de Mirante do Paranapanema, São Paulo, Brasil. Veterinária e Zootecnia, v. 17, n. 1, p. 47-53, 2010.

SANTARÉM, V. A.; FRANCO, E. C.; KOZUKI, F. T.; FINI, D.; PRESTES-CARNEIRO, L. E. Environmental contamination by Toxocara spp. eggs in a rural settlement in Brazil. Revista do Instituto de Medicina Tropical de São Paulo, v. 50, n. 5, p. 279-281, 2008.

SANTARÉM, V. A.; PEREIRA, V. C.; ALEGRE, B. C. C. P. Contamination of public parks in Presidente Prudente (São Paulo, Brazil) by Toxocara spp. eggs. Revista Brasileira de Parasitologia Veterinária, v. 21, n. 3, p. 323-325, 2012.

SANTARÉM, V. A.; SARTOR, I. F.; BERGAMO, F. M. M. Contaminação, por ovos de Toxocara sp., de parques e praças públicas de Botucatu, São Paulo, Brasil. Revista da Sociedade Brasileira de Medicina Tropical, v. 31, p. 529-532, 1998.

TIYO, R.; GUEDES, T. A.; FALAVIGNA, D. L.; FALAVIGNAGUILHERME, A. L. Seasonal contamination of public squares and lawns by parasites with zoonotic potential in southern Brazil. Journal of Helminthology, v. 82, n. 1, p. 1-6, 2008. 